\title{
RESPONDER AL DESPRECIO. NietzSCHE Y LA GENEALOGÍA DE LA LiTERATURA DE TEMÁTICA HOMOSEXUAL EN COLOMBIA
}

\author{
RESPONDING TO CONTEMPT. NiETZSCHE AND A GENEALOGY OF HOMOSEXUAL LITERATURE \\ in Colombia \\ RÉPONDRE AU MÉPRis. NiETZSChE ET LA GÉNÉALOGIE DE LA LITTÉRATURE HOMOSEXUELLE \\ en Colombie
}

\begin{abstract}
Alexánder Hincapié García
Doctor en Educación, Universidad de Antioquia. Docente investigador, Tecnológico de Antioquia Institución Universitaria, Medellín, Colombia. Calle 78B N. ${ }^{\circ} 72 A-22$, Tecnológico de Antioquia Institución Universitaria, Medellín, Colombia alexander.hincapie@tdea.edu.co
\end{abstract}

\begin{abstract}
RESUMEN
La literatura de temática homosexual en Colombia puede entenderse como un esfuerzo por responder al desprecio habitual con el que son representados los homosexuales. El desprecio es un lenguaje mímico de afectos, con capacidad de vincular distintas fuerzas sociales dirigidas contra determinadas formas de vida. La perspectiva teórico-metodológica adoptada se aproxima a la genealogía propuesta por Nietzsche. Por ello, no se entiende la búsqueda de origen alguno, sino el trabajo de producir interpretaciones que interrumpan la cadena de signos y significados socialmente aceptados.
\end{abstract}

Palabras clave: desprecio, genealogía, homosexual, literatura colombiana, Friedrich Nietzsche

\begin{abstract}
Homosexual literature in Colombia can be understood as an effort to respond to the habitual contempt with which homosexuals are represented. Contempt is a mimic of affections capable of linking different social forces directed against certain forms of life. The theoretical-methodological perspective adopted approximates the genealogy proposed by Nietzsche. Therefore, genealogy is not the search of any origin, but it is the work of producing interpretations that interrupt the chain of socially accepted signs and meanings.
\end{abstract}

Keywords: contempt, genealogy, homosexual, Colombian literature, Friedrich Nietzsche

\section{RÉSUMÉ}

L'homosexualité dans la littérature colombienne peut s'envisager comme une réponse face au mépris généralisé envers les homosexuels. Le mépris est un langage gestuel des affects qui permet de véhiculer différentes forces sociales à l'encontre de certaines formes de vie. L'approche théorique-méthodologique dans la- 
quelle nous nous inscrivons, est proche de la généalogie proposée par Nietzsche. Il s'agit donc d'un travail interprétatif qui rompt la chaîne des signes et des signifiés socialement acceptés et non d'une recherche sur leurs origines.

Mots-clés : mépris, généalogie, homosexuel, littérature colombienne, Friedrich Nietzsche 
¿Por qué hemos de conquistar el derecho a vivir una y otra vez, cada día de nuevo, cada vez que vuelve a salir el sol? Leon Uris (1971, p. 636)

\section{Introducción}

La influencia de Nietzsche no está agotada. Esto se demuestra en el libro editado por Simon May (2011) acerca de La genealogía de la moral. Este plantea que la obra de Nietzsche, inabarcable en temas, problemas y estilos, es una fuente provocadora de reflexiones morales imposibles de desechar. Nietzsche (2001) anticipa su vigencia singular al referir que su autoridad se debe a que no se le comprende. Es póstumo, no tempestivo, un hombre imposible de comprender de manera plena. Por lo tanto, el pensamiento filosófico queda inevitablemente abocado a una no clausura del texto nietzscheano. ${ }^{1}$

Situándose en el contexto colombiano, los trabajos de Ignacio Abello, Jesús Ferro Bayona y Mónica Zuleta Pardo son interesantes para pensar la vigencia y los usos de la filosofía de Nietzsche. En específico, Abello (2003) investiga la cuestión de la violencia y la cultura, sirviéndose tanto de Nietzsche como de Foucault en cuanto referentes teórico-metodológicos. Derivado del pensamiento del filósofo alemán, Abello aprecia que el hombre es el único animal que se hace promesas y la primera es la de darse la humanidad a través de la formación (Bildung). No en vano, hay que reparar en esa promesa para pensar la relación entre violencia y cultura. A su vez, Ferro (2004) plantea que la importancia de la filosofía de Nietzsche estriba en la voluntad de expresar la construcción

1 Para Rujas Martínez-Novillo (2010), en torno a Michel Foucault hay consenso sobre el valor de su pensamiento. Continuadores como detractores, directa o indirectamente, lo citan para el desarrollo de sus proyectos intelectuales. Sin embargo, son escasos los trabajos que reflexionan la importancia que tiene Nietzsche en el pensamiento de Foucault, como si una suerte de iluminación permitiera captar las consecuencias de un pensamiento sin reparar en el espesor que lo precede. del sentido de manera diferente. Esto convierte en necesario explorar otras figuras del lenguaje, distintas a las que recurre normativamente el lenguaje conceptual. Por su parte, Zuleta (2011) propone una genealogía de la verdad en torno a la violencia en Colombia. Con conceptos desarrollados por Nietzsche, desprende que la verdad no es la comprensión de un hecho dado, sino la fabricación de objetos que se postulan presentes antes de toda interpretación, negando la voluntad que los hizo posibles.

Como en los trabajos relacionados, en este artículo Nietzsche es invaluable. Dicha importancia puede asociarse a tres aspectos de orden teórico-metodológico: el primer aspecto se relaciona con el rechazo de las "modas" intelectuales que obligan a remitir toda pregunta de investigación hacia la decolonialidad o a la "perspectiva” de género (Hincapié García, 2015). Un tipo de obligación semejante a un moralismo académico que establece aquello que debe imperar en el juego de la verdad con la máscara de la reparación histórica. Nietzsche es una oportunidad para explorar recursos estéticos y literarios abandonados, pero capaces de renovar las interpretaciones disponibles para la vida cultural en el presente.

El segundo está asociado con el perspectivismo. Según Nehamas (2002), este consiste en la obliteración de toda clasificación que reduzca las distintas formas de vida a una interpretación clausurada y única. Toda interpretación es una práctica valorativa y la libertad consiste en desarrollar la fuerza para crear valores. En este sentido, para Nietzsche, no es en la ética de Kant donde debe buscarse el cómo dar forma a una vida ejemplar y bella, sino en la inspiración que viene de los griegos (Lemm, 2013). Incluso, esta pregunta, si se convierte en un criterio pedagógico general, carece de importancia, en la medida en que una vida ejemplar y bella no puede prescribirse para todos. Una vida tal no puede enseñarse. Esta solamente es posible para los hombres que luchan 
por conquistarla. Más importante que la libertad como un derecho, es la libertad que los hombres se dan para sí, a riesgo de la vida misma.

El tercer aspecto tiene que ver con el texto. Para Sedgwick (1998), cuando se penetra el texto nietzscheano, se precipitan sentimientos exacerbados e intensos hacia los hombres y el cuerpo masculino. Empero, lo que prolifera son interpretaciones académicas y noveladas sobre Nietzsche y las mujeres (Atala, 2014; Derrida, 1981; Diethe, 1996; Oliver y Pearsall, 1998; Patton, 1993). De hecho, los estilos escriturales de Nietzsche sirven para renovados ataques contra la homosexualidad: candidez, debilidad, inversion, afeminamiento/varonil, fuerza, virilidad, súper hombre. Su obra coincide históricamente con la captura moderna de la sexualidad y la angustiosa pregunta por si los hombres atraídos eróticamente por otros deben considerarse femeninos (conforme al modelo explicativo inglés) oviriles (a propósito del derrotado modelo griego). Sedgwick (1998) argumenta que Nietzsche jamás hizo de la atracción entre hombres un problema a discutir. Esto puede suponer que esa atracción es aceptada o es la condición del pensamiento mismo. En Humano, demasiado humano, Nietzsche (2013) elogia la comunidad de hombres creada por los griegos y, en el elogio, la afirma como un vinculante valor cultural de enorme belleza.

El recurso a Grecia no debe ignorarse o ser tratado como un juego afectado o estilístico. A lo largo de la historia, este recurso no es un mero modo de aludir a una época "superada", en la cual el cuerpo masculino sirve de referente para la belleza, sino el (único) medio a través del cual se ingresa dicho cuerpo para la veneración estética de los hombres. Nótese el período renacentista (Pater, 1999). Nietzsche parece saberlo. Su oposición a la moral cristiana, su defensa del arte griego y su repulsión por la Modernidad, teatraliza una lucha turbulenta entre los ideales sacerdotales negadores de la carne y la actividad estética afirmadora del cuerpo. A su juicio, la Modernidad es una época contraria a la fisiología (una manera de nombrar las fuerzas vitales y las afecciones). Por esto,
Nietzsche ofrece una obra de abierta seducción, al estilo de Whitman, y de gran belleza sobre la unión entre hombres; pero lo hace con la ausencia obstinada, quizá incluso estudiada, de cualquier generalización, alabanza, análisis y cosificación explícitas de estos vínculos que permita pensar que se prefieren específicamente a personas del mismo sexo (Sedgwick, 1998, p. 178).

Dicho lo anterior, se entiende por genealogía la práctica interpretativa de la transvaloración (Umwertung). Con frecuencia se imagina que esto es invertir, destruir o hundir los valores. La genealogía en Nietzsche (2005) es algo más complejo y sutil. Se le comprende mejor como la sustitución de unos valores por otros; dígase, la preeminencia de los valores aristocráticos (creadores) sobre los resentidos (calumniadores). Mientras los primeros se entienden como la fuerza de la afirmación, los segundos son carentes de contenido, están vacíos sin los opuestos contra los cuales remachan su resentimiento. El mismo Nietzsche dirá que esta dialéctica es un ataque a los instintos.

El artículo está organizado en tres partes. La primera, titulada "Escenas del desprecio", se ocupa de presentar la atmosfera cultural inducida por diferentes figuras públicas en Colombia en torno a la homosexualidad. La característica básica de esta atmosfera es el desprecio; en todos los casos, expresado en una amalgama extraña de valores religiosos y criterios moderno-científicos.

"La literatura como respuesta" es la segunda parte. A través de tres configuraciones de respuesta y una fuga, se plantea que la literatura puede entenderse como un esfuerzo por responder al desprecio con el cual son representados los homosexuales en Colombia; esfuerzo que se abre camino en la ficción y que ofrece a los hombres la posibilidad de imaginar la homosexualidad a través de formas de vida deseables.

Finalmente, "Entre hombres", es la tercera parte. Se reflexiona sobre la importancia de la literatura de temática homosexual en Colombia, para estudiar no solo la homosexualidad, sino también los 
modos de organización y gestión cultural del país con respecto a su diferencia. Asimismo, es una oportunidad para vigorizar la afirmación de sí recurriendo al desprecio como combustible.

\section{Escenas del desprecio}

La genealogía no establece extensas líneas de continuidad, ni representa el cambio histórico como evolución o progreso. En el acontecimiento histórico, advierte el espesor sedimentado que separa lo que en un momento se levantó como el enunciado verdadero frente a todo lo que, hundido, no pudo vencer en el juego de la verdad. Más exacto, la genealogía muestra, en las rupturas y las discontinuidades, las escansiones de problemas recurrentes o la aparición de nuevos problemas para la vida social.

En este sentido, devolver al presente el desprecio de la homosexualidad que aparece en las letras de figuras públicas de diferente estofa como Luis López de Mesa, Israel Rojas, Miguel Echeverry y Pedro Restrepo Peláez, no supone una relación histórica de continuidad y de evolución que los vincule. No hay en sus enunciados una deducción que permita representarles dentro de una "tradición" organizada de desprecio de la homosexualidad. Al contrario, lo que puede deducirse es la posibilidad de que dicho desprecio se exprese siempre, para pontificar sobre la necesidad de enfrentar las formas de vida que la homosexualidad promete y que se perciben como una amenaza a la cultura, la sociedad y la familia (Foucault, 2015).

Por desprecio se entiende un lenguaje mímico de afectos (Ávila, 2008), esto es, un conglomerado de símbolos, metáforas y analogías que hacen posible la vinculación entre los miembros de una sociedad. El presente apartado se organiza a través de cuatro figuras claves, cada una asociada a una escena: Luis López de Mesa, "Vida e instinto"; Israel Rojas, "La homosexualidad, el azote de la raza”; Pedro Restrepo Peláez, "La decadencia del arte por la homosexualidad”, y Miguel Echeverry, "El hippie, perversión e inversión". Lo que se expone es la atmosfera cultural colombiana que persiste en descalificar la homosexualidad para justificar su desprecio. A esta persistencia, como se verá, la literatura de temática homosexual responde de manera oblicua, ofreciendo otras formas de vida.

\section{Vida e instinto}

Antes de ser nombrado ministro de Educación durante el gobierno de Alfonso López Pumarejo, Luis López de Mesa publica, en 1926, Civilización contemporánea. Este ensayo explora los problemas de la formación de las naciones, las determinaciones raciales, el papel de la educación y el futuro de la civilización. Su escritura responde a la urgencia angustiosa de un intelectual que reflexiona el futuro, sin renunciar a la devoción por los órdenes del pasado: la sangre y la herencia.

Uno de los problemas reflexionados tiene que ver con el nexo entrevida einstinto. Para Lópezde Mesa (1926), la vida se desplaza hacia el futuro con la amenaza de las fuerzas atávicas del pasado y el hedonismo de las civilizaciones agotadas. Los instintos del hombre son amenazados por algunas emociones extrañas, ciertas teorías conturbadoras y el anarquismo moral. En el corazón de esas amenazas está el "escaso" mérito que se le concede al amor heterosexual, al intento de explicar la "inversión" erótica como una posibilidad ofrecida por la naturaleza o al triunfo de la "inversión" en el psiquismo de hombres equívocos.

López de Mesa, sin embargo, considera la posibilidad de que la "inversión" erótica tenga una base biológica, sin descartar el vicio y la perturbación psíquica. Extraña, conturbadora y anarquista, la homosexualidad es el descaro manifiesto que duda de la existencia del sentimiento y la sexualidad normal de los hombres. Con todo, los homosexuales no son peligrosos, supone López de Mesa, retórico, convenciéndose a sí mismo. El nexo entre vida e instinto se confirma en la familia y esta "continuará siendo la célula social por excelencia; y que ningún comunismo ni desviación 
sexual, ni embriaguez hedonista, lograrán destruirla” (López de Mesa, 1926, p. 99).

El desprecio de la homosexualidad que desborda la "pluma" de López de Mesa es el ademán que la reconoce como una amenaza, al tiempo que sus "practicantes", los homosexuales, son imaginados sin fuerzas suficientes para producir el cambio histórico.

\section{La homosexualidad, el azote de la raza}

En un aforismo de Humano, demasiado bumano, Nietzsche (2013) refiere: si no se tiene un buen padre, habrá que conseguir uno. Israel Rojas Romero (seudónimo Raghozini), figura desconfiada con respecto a la influencia cultural de Nietzsche y de Freud, es considerado por la Fraternidad Rosacruz como su "padre" en Colombia. Lo importante no es decidir qué tipo de padre resulta ser, sino destacar su actividad como director de la Fraternidad Rosacruz Antigua de Bogotá, desde 1928 hasta 1985 — fecha en la que, según sus seguidores, se evaporó de este plano inferior-. En Colombia todavía se difunden sus enseñanzas como un saber para hombres superiores e iniciados. Hombres que se elevan por encima de los meros sentidos y de la materia. Probablemente, la desconfianza dirigida contra Nietzsche y Freud se relacione con el énfasis del primero en el cuerpo, los sentidos y los afectos y la negativa del segundo a aceptar que los seres humanos posean virtudes de una naturaleza superior.

Entre sus variopintos escritos destacan Dignificación femenina, El fantasma de los siglos, El enigma del hombre o Cultura intima del joven. De entre ellos, vale reseñar Los grandes azotes de la raza. En este, Rojas (1947) aclara que las dos ciencias más importantes son la biología y la psicología. Con ellas estructura una especie de matriz interpretativa que relaciona con la ciencia cuántica. En concreto, su preocupación es la de revelar las causas de la degeneración racial. ${ }^{2}$ Aunque optimista - sostiene que la raza puede mejorarse si se le interviene.

Resulta interesante destacar que la preocupación se produce en el período en el que Europa, vía el nacionalsocialismo alemán y el ascenso de Hitler al poder, convierte la selección y el perfeccionamiento racial en una cuestión determinante para la organización de las sociedades. ${ }^{3}$ Para Rojas, la raza está amenazada por múltiples cuestiones. Pese a todo, hay tres de ellas que resultan más problemáticas: la herencia, el alcoholismo y la masturbación. En un giro particular, aunque no inédito, desprende de la última las posibilidades de fantasear y realizar la homosexualidad, la más aberrante y abyecta de las degeneraciones - declara-. ${ }^{4}$ Instiga por una educación sexual que no esconda nada, que acepte la existencia de la masturbación y de la homosexualidad, pues, a su juicio, es en la ignorancia y la negación de su existencia donde se halla su fuerza realizativa. Es decir, ignorar o negar la masturbación y la homosexualidad es la mejor forma de realizarlas.

Parecerá extraño, pero el desprecio que Rojas expresa por la homosexualidad reclama una educación "liberadora" que la haga visible. Años más tarde, serán los mismos activistas por los derechos

2 Para Castro Gómez (2007), la polémica de la degeneración de la raza, por lo menos en términos formales, se cierra en 1934. Sin embargo, puede sugerirse, a propósito de Israel Rojas, que la polémica permanece abierta hasta finales de los años cuarenta.

3 Para una perspectiva sobre este tema se sugiere el trabajo de Borovinsky y Taub (2009), donde se expone cómo el genocidio es una poderosa fuerza de destrucción y reconstrucción de las relaciones sociales.

4 Se dice que el giro no es inédito, porque en la misma época, Forster y Giraldo (1934) expresan el peligro del "niño mentiroso": oculta la masturbación y comparte "amistades particulares". 
de los homosexuales los que lanzarán arengas en torno a la "necesaria" visibilidad.

\section{La decadencia del arte por la homosexualidad}

Pedro Restrepo Peláez viaja desde temprana edad por varios países de América Latina, educándose en diferentes artes. También se desempeña como vicecónsul de Colombia en París. Se le define como servidor público, artista y escritor polémico. En 1969 publica uno de sus libros más conocidos: El homosexualismo en el arte actual.

Alfonso López Michelsen, fundador del Movimiento Revolucionario Liberal y años más tarde presidente de Colombia, refiere en el prólogo escrito para el libro de Restrepo, que este no toma partido ni juzga a los que practican el amor, que no dice su nombre, sino que expone con rigor científico las funestas consecuencias de la intromisión de los homosexuales en el arte actual.

Autor y prologuista se funden en su semejanza. Sus ideas no difieren, recíprocamente se enlazan una sobre la otra, para expresar su desprecio. Restrepo encuentra que son necesarios más trabajos de historia y psicología que puedan aclarar la situación a la cual se conduce el arte por la presencia de los homosexuales. Seres enfermizos y limitados. Se equivocan los que imaginan que hay

5 Para Bersani (1998), en el reclamo de visibilidad, de manera implícita, se incluye la aceptación de la vigilancia. Por lo mismo, más que convertir en una meta la visibilidad política, los homosexuales pueden redescubrir los placeres del anonimato. Esto para nada se constituye en una petición de "volver" a los armarios, sino de no confundir la creación de espacios para el placer entre los hombres con la normalización de espacios sociales para la realización de una "correcta" homosexualidad. Estos últimos, al final, sacrifican el placer que históricamente la hace deseable. En todo caso, la presencia (visibilidad) o la ausencia (anonimato) de la homosexualidad debe negarse a los censores sociales y tiene que responder al esfuerzo de los mismos homosexuales por intensificar su placer. Mostrarse o esconderse no puede responder a nada distinto que a la búsqueda por explorar otras posibilidades del placer homosexual. en ellos inteligencia alguna o capacidad creadora. No es posible, porque estos hacen del sexo un fin en sí mismo. En el arte, las letras y la literatura, los homosexuales abren su camino. Sin embargo, el peligro del uso expresivo por estos medios es que los homosexuales no pueden ver el mundo desde un punto de vista que no sea el suyo, esto es, un punto de vista falso y distorsionado. Por lo tanto, la homosexualidad es una anomalía y una infamia. La anomalía reclama ser tratada, controlada y erradicada. La infamia, a su vez, indica que el homosexual, en sentido estricto, no puede considerarse un hombre de verdad. ${ }^{6}$

Restrepo (1969, p. 24) afirma que su preocupación es el arte y, por lo mismo, prefiere "no" emitir juicios que corresponden a las autoridades censoras.

Este escrito representa un ejemplo estimulante en torno a cómo el pensamiento liberal y progresista no necesita romper con un lenguaje de desprecio. Al contrario, puede prolongarlo, por medio de usos en los cuales se afirma que lo dicho es la expresión del canon científico o artístico correcto.

\section{El hippie, perversión e inversión}

Los años sesenta y setenta son prolíficos en la aparición de movimientos pacifistas, anticulturales y de liberación sexual. Un tipo de subjetividad producida por aquella época es la de los hippies. Herederos de la Generación Beat, exploran los límites de la conciencia y del cuerpo, en un esfuerzo por derribar los lugares de sujeto en los cuales son hundidos los hombres y las mujeres con todas sus expectativas en torno a un mundo distinto. Los hippies crean usos culturales que desafían la orientación hacia el progreso, la política militar y las restricciones sexuales.

6 Una forma de lanzarlos a una zona ontológica inviable. Los homosexuales son esa extraña paradoja donde, a desgano, se juntan el reconocimiento de su humanidad y la imposibilidad de aceptarla. Este tipo de paradojas antropológicas pueden estudiarse en el reciente trabajo de Juan David Piñeres Sus (2017). 
En Colombia, puede decirse que ese desafío es atacado desde tres frentes: el religioso, el pedagógico y el psicológico. Sin mucho esfuerzo, Miguel Echeverry (1971) aúna estos tres frentes en su libro Psicopatología y existencia del hippie.

Este texto es una exposición de la conducta normal que promueve una idea de "gran" alcance: el hippie es un enfermo mental, un esquizofrénico. Para Echeverry, su postura se desprende de un análisis médico-psiquiátrico. Los síntomas del hippie se articulan en cinco grupos: el primero incluye a los de relaciones personales defectuosas (autistas); delirantes y egoístas, presumen de una singularidad que no es más que un defecto. El segundo se refiere a los agresivos; rebeldes, desafiantes y disputadores, rechazan la autoridad paterna. En el tercer grupo se ubican los de conducta anómala, producto de la desadaptación sociofamiliar. El cuarto grupo está constituido por individuos de afectividad deficiente o, en otras palabras, que padecen embotamiento afectivo. Por último, en el quinto grupo se representan a los individuos de instintos anormales: perversos e invertidos.

En palabras de Echeverry (1971), Dios imprime en el hombre una perfección que algunos individuos niegan. En el uso del pelo largo y la barba, el hippie esconde la perversión y la inversión sexual negadora de dicha perversión. De pronto, el precepto de la Torá por el cual al varón se le prohíbe cortar el vello del rostro, se convierte un criterio de “inversión" sexual. ${ }^{7}$ Añade que no hay dignidad alguna en la actividad erótica del hippie, porque no hay dignidad en una sexualidad presentada como libre. El hippie es un cínico capaz de arrojarse en una sexualidad que no diferencia los sexos, "cayendo descaradamente en otra grave y vergonzosa anormalidad sexual: la homosexualidad" (Echeverry, 1971, p. 72).

7 En el Zohar (Anónimo, 1994), libro que pertenece a la cábala judía, se afirma que del que preserva su barba puede afirmarse que es un hombre fiel.
En el plexo donde se juntan tanto como se separan estas cuatro escenas, se alza una inferencia. Despreciar la homosexualidad es la expresión de una fantasía: aquella a través de la cual hombres y mujeres se protegen, de manera fallida, de su efecto contaminante y seductor. Sedgwick (1998) sostiene: el pavor que la homosexualidad despierta tiene como contracara la fascinación que produce en aquellos que cuantifican el daño que (les) puede causar. En su modo extremo, un pathos que lucha por destruir aquello que ha convertido en el objeto de su fascinación. En esta medida, el desprecio de la homosexualidad, ese vínculo social paranoide y reaccionario, es el deseo inhibido que la reclama siempre allí como condición de posibilidad para desear la heterosexualidad.

\section{La literatura como respuesta}

\section{Clava en mi carne el acerado garfio de un extraño tormento \\ Porfirio Barba-Jacob (1983, p. 91)}

En Historia maldita de la literatura, Meyer (1977) afirma que los judíos y los homosexuales son dos de las grandes exclusiones históricas de Occidente. Dichas exclusiones son variables, en la medida en la que no se producen siempre de manera simultánea y con la misma intensidad, o que respondan a dispositivos idénticos.

En su estudio sobre Nietzsche, Kofman (1994) sostiene que solo una lectura vulgar convierte a Nietzsche en el gran enemigo judío. Nietzsche reconoce que estos son los maestros en el arte de superar el desprecio, porque aman la vida afirmándola y cultivando su diferencia. Así, los judíos responden al desprecio con más desprecio. Aquí se sostiene que la homosexualidad responde del mismo modo. Lo urgente consiste en precisar cuál es el contenido de ese desprecio. Adviértase, no puede ser igual al desprecio frente al que se responde, pues no se trata de una contrarrespuesta reaccionaria.

La interpretación propuesta informa que tanto el desprecio de los judíos como de la homosexualidad 
tiene como contenido la escritura y la invención de estilos escriturales y narrativos. Es decir, judíos y homosexuales acuden a un desprecio creador. Por tradición, el judío es el pueblo del libro, característica que está a la base del judio de saber. ${ }^{8} \mathrm{~A}$ su vez, en la literatura, la homosexualidad descubre cómo responder al trauma cultural producido a finales del siglo XIX con la construcción de los homosexuales como objetos de la psiquiatría. ${ }^{9}$ Por lo pronto, se habla de literatura de temática homosexual y no de una "literatura homosexual". Alzate (2002) afirma que no hay una literatura sin adjetivos, aunque esto no permite suponer, sin más, una "literatura gay" o una "literatura femenina" — por mencionar dos recursos clasificatorios-.

Con respecto a la selección de las fuentes literarias, el artículo se delimita a partir de algunas novelas de autores colombianos, publicadas entre 1932 y 2016. Se excluyen las crónicas, los escritos biográficos o las narraciones de periodismo literario en los que el elemento investigativo formal compite con la ficción. Por ejemplo, los trabajos de Gonzalo García Valdivieso (2010 y 2016).

Inscrito en el trabajo iniciado por Daniel Balderston (2004, 2006 y 2015), este artículo se abre a través de tres posibles configuraciones de respuesta y una fuga. Por esto se entiende el uso

8 Milner (2008) plantea que judío y saber se entrelazan recíprocamente. De hecho, podría pensarse que los dos nombres (acéptese la personificación) se acompañan de manera solidaria. Sin embargo, este enlace no es un privilegio. Antes bien, expresa una excepción, para algunos divina, para otros histórica. Lo que aparece constante es el intento por romper este enlace, incluso, si el costo es el exterminio.

9 Se afirma que la homosexualidad responde con las letras y con ello no se está indicando que quienes responden, siempre, sean los homosexuales. Puede decirse que muchos autores, por distintas razones, encuentran en la homosexualidad una posibilidad de erosionar el canon estético literario. A lo mejor, como en el caso de Deleuze y Guattari (2004), no se trata de una homosexualidad literal, sino molecular. Esto quiere decir, la atracción entre hombres como una fuente de reflexión filosófica y estética. imprevisto de enunciados y prácticas discursivas que, al entrecruzarse, producen un vector de fuerza (Foucault, 1996). De manera sumaria, a continuación se caracterizan, siguiendo algunas novelas que sirven de referentes. ${ }^{10}$

\section{Expiación y sufrimiento}

Para Ahmed (2015), es habitual que los sentimientos se representen como privados, es decir, expresiones de orden personal, sustraídas de la dimensión pública. El sufrimiento se imagina como aquello que encarna en los individuos, sin más. No obstante, hay que preguntar en qué punto los sentimientos y la política se entrecruzan, si se reconoce que determinados sujetos históricos, de manera permanente, deben aceptar la expiación y el sufrimiento como sentimientos que dan forma a sus vidas.

En el caso de este trabajo, la homosexualidad, más que una afección personal, es el cabo antagónico de uno de los nudos que constituyen la Modernidad occidental (Sedgwick, 1998); cabo sobre el cual recae la contradictoria obligación de dar cuenta, justificar y negarse a sí mismo, a través de la expiación y el sufrimiento que se impone a los homosexuales como parte de su comparecencia ante el tribunal de la historia.

Esta configuración tiene su emergencia en un importante gesto inaugural dentro de la literatura en Colombia (Hincapié García, 2011). En concreto, se habla de la novela de culto Por los caminos de Sodoma, de 1932. Su autor, Bernardo Arias Trujillo (2012b), explora el desamparo, la frustración y la humillación de un hombre que experimenta, desde su infancia, una atracción

10 Plegados al ensayo de Balderston (2006), Baladas de la loca alegría, podría afirmarse que la genealogía que aquí se propone, de manera indirecta, también comienza con un outing (sacar del armario a alguien). En 1914, el guatemalteco Rafael Arévalo Martínez (1963) expone como homosexual a Porfirio Barba-Jacob en el cuento El hombre que parecía un caballo. Otro trabajo importante de reseñar es la antología preparada por Óscar Castro García, Un siglo de erotismo en el cuento colombiano (2004). 
erótica y afectiva por su mismo sexo. ${ }^{11} \mathrm{El}$ desenlace, más que manifestar las consecuencias de una afección equívoca, expone la imposibilidad cultural para dar un lugar no signado por desprecio a un eros persistente en la civilización occidental (González Iglesias, 2001).

Tal vez no de manera directa, el gesto iniciado por Arias Trujillo puede percibirse en tres novelas más que cubren un espacio temporal entre 1973 y 2015 .

En 1973, Hernán Hoyos publica Nadie conoce mi sexo. En un relato que juega con los recursos de la narrativa de ficción y la biografía, se explora la lucha de los hombres homosexuales por la aceptación de sí mismos y su imposibilidad. El suicidio es, pues, un modo fallido mediante el cual se afirma una voluntad..$^{12} \mathrm{Al}$ final, una nota de los editores: "Los manuscritos de Óscar Montoya han sido publicados con la autorización legal de sus herederos más próximos, quienes trasladaron sus restos mortales al cementerio metropolitano de Cali" (Hoyos, 1973, p. 274).

Unos años más tarde, en 1977, Jorge Gómez publica Uno bajo el signo de Escorpión. El fantasma del suicidio y de la desaparición atraviesa toda la novela. Tal vez por eso el yo narrador lanza una provocación al lector: "dos hermanos se amaron, se unieron carnalmente" (Gómez, 1977, p. 28), y frente a la negación de cualquier término no degradado que permita nombrar ese amor, "uno de ellos, estando en el batallón, fue a la enfermería, accionó con el dedo gordo del pie el disparador de un fusil cuyo cañón apuntaba al cráneo" (Gómez, 1977, p. 28). Figurativamente, el tiro en la cabeza que estalla los sesos en todas las

11 En el año 2012, la novela de Arias Trujillo fue reeditada con el seudónimo Sir Edgar Dixon entre paréntesis.

12 Sedgwick (2002) denuncia que gran parte de los suicidios de los adolescentes tienen que ver con la imposibilidad de recibir apoyo en la afirmación de la homosexualidad. Estos suicidios no responden a una psicología equívoca y patológica, sino al empuje cultural que reclama la muerte de los homosexuales. direcciones es la imagen de la razón que se vuelve contra sí misma, incapaz de crear un lugar para otras formas de vida.

De manera temporal, la configuración de respuesta aquí presentada puede cerrarse con la reciente novela de Alfonso Carvajal, Ruega por nosotros (2015). Deleuze (1980) sostiene que se escribe por amor; todo libro es una carta, una declaración de afectos. Del mismo modo, puede advertirse que se escribe para dar testimonio de lo intestimoniable, esto es, la vida y la muerte.

El libro de Carvajal recoge mucho de lo anterior. Dos sacerdotes católicos enamorados, René y Rómulo, intentan esconderse de la sociedad, pero no pueden esconderse de sí mismos. El contagio por el VIH/SIDA precipita un desenlace fatal, a través de un pacto sellado con la muerte comprada a los sicarios. La novela, una reconstrucción literaria a partir de un hecho ocurrido en el año 2011 en la ciudad de Bogotá, sin proponérselo, da cuenta de la furia recurrente en contra de los homosexuales. ${ }^{13}$

Walter Benjamin (2010) afirma que felicidad es vivir una vida sin miedo. Si este criterio es correcto, estas tres novelas denuncian la escasa posibilidad de la felicidad para los hombres homosexuales en Colombia.

\section{Ironía y desencanto}

Te quiero mucho poquito nada, del artista plástico Félix Ángel (1975), es la primera novela que podría situarse en esta configuración. La ciudad de Medellín, una aldea que crece sin que eso modifique la formación de su gente, se explora y describe como una ciudad conservadora y escandalizada con lo que arranca a la vida de los hombres para convertirlo en escarnio público. Sin embargo, en una ciudad obsesionada con las "buenas costumbres", lo determinante de la valoración moral

13 Gustavo Álvarez Gardeazábal (2014) también hará eco de este hecho para su novela La misa ha terminado. 
de las acciones recae en el dinero: "Una mujer casada que se acuesta con otro no es puta si tiene plata y si un señorito se come a otro no son maricas, no señor. Son modernos" (Ángel, 1975, p. 91).

Pipe, el yo narrador de Ángel, es el niño que se hace hombre. Quería ser feliz y no pudo. No hay grandes dramas, solo desencanto y un gesto nostálgico con

[...] la corazonada furtiva de que las cosas queridas inexactamente se alejan Playa abajo con las luces de los carros y el cambiar cronometrado de los semáforos, deteniendo, avisando y dando paso a la vida, a la maravillosa vida. FIN (Ángel, 1975, p. 185).

En esta misma configuración podría situarse el conjunto de la obra de Fernando Vallejo. Desde la autobiografía publicada entre 1985 y 1993 , con el título El río del tiempo, ${ }^{14}$ pasando por $E l$ mensajero, La Virgen de los sicarios y Mi hermano el alcalde, Vallejo expone las relaciones homosexuales, no como algo exterior a la formación del colombiano, sino como aquello que la constituye.

En El desbarrancadero, el yo narrador de Vallejo (2008) reflexiona las muertes de su padre y la de su hermano Darío. En uno de los diálogos expresa: “-Los muchachos, Darío - le increpé-, son un bien público, no propiedad privada. Que los tome el que quiera y los pueda pagar. ¡O qué! ¿De viejo que te va a entrar la posesiva?" (Vallejo, 2008, p. 50).

No hay una reivindicación ni un esfuerzo por situar su literatura en los estudios de género, ni tampoco hace un llamado a la sociología o a la defensa de los Derechos Humanos. Más radical, Vallejo pone la homosexualidad en el centro de la vida social.

De manera irreverente, se anticipa a que su obra sea recuperada por la "corrección" política. En El don de la vida se burla de los valores liberales, afirmando que "las palabras 'pederasta', 'misógino' y 'vegetariano' no me gustan. Son cultismos, o idioteces” (Vallejo, 2010, p. 138).

14 Incluye Los dias azules, El fuego secreto, Los caminos a Roma, Años de indulgencia y Entre fantasmas.
Nótese que de su literatura no se desprende ningún imperativo de "corrección” política. No regala la posibilidad de reivindicación alguna que pueda ser capturada por el activismo social. Como bien expone Balderston (2004), Vallejo se da para sí la preeminencia de un dandy opuesto a la celebrada diversidad sexual en cuanto esta es pura mercancía multicultural.

Por su parte, Rubén Vélez (2001) publica Veinticinco centimetros. Dos "locas", afectadas y barrocas, recorren la ciudad de Medellín, presentándola al lector que las acompaña: edificios, motos, sicarios, arribistas, maricas y viejas del montón. Al final, tal vez un único motivo de celebración: la maravillosa verga de James. Veneración y delirio por un órgano vituperado y declarado enemigo público por un cierto feminismo puritano (Friedman, 2007). Como dirá Vallejo de los muchachos, la verga de James se eleva como un bien público a disposición de todos. De cierto modo, la homosexualidad no se entiende plenamente, sino es por el amor devoto y la fascinación por la verga.

Dos años después, por medio de estereotipos y clichés, Alonso Sánchez Baute (2003) explora el significado de la identidad socialmente construida para la homosexualidad en Colombia. Edwin Rodríguez Buelvas, personaje principal de la novela, reúne lo "deplorable" del homosexual despolitizado: impostura, pobreza y arribismo, actitud vacua que, de fiesta en fiesta, intenta, sin alcanzarlos, el "triunfo" como drag queen y el amor de su vida (Díaz Ruiz, 2010).

La ironía y el desencanto de esta configuración, si se extrae su contenido de las novelas aquí reseñadas, corresponden principalmente a dos aspectos: el primero se refiere a una crítica sin descanso a las formas sedimentadas de la modernización en Colombia y a sus complejos culturales (Arias Trujillo, 2012a); el segundo está relacionado con la simultaneidad de los tiempos históricos que se expresan en cada situación dramática de lo narrado (tiempo teológico/tiempo secular) y con el conflicto permanente entre la tradición 
(entendida como atavismo) y las fuerzas vitales. Es decir, capturada por las costumbres y la religiosidad, la tradición aparece como lo que se opone a lo único que une al hombre con la naturaleza: las fuerzas creadoras y radicales de la diferencia.

\section{Encontrar(se)/otro cuerpo}

Para Deleuze (2006), la última oportunidad que está en juego para el hombre es la de devenir revolucionario. Con ello, el rechazo de lo intolerable. Si las letras son capaces de doblar el arco que apunta en contra de la vida, entonces hay que hacer de la escritura el arte que resiste toda forma de desprecio que no sea creador. La última configuración de respuesta dentro de este artículo tiene un punto de emergencia en los recientes años noventa.

No sin discusión entre un comité de jurados, en el que se encuentra Héctor Abad Faciolince (Hincapié García, 2009), en 1992, con Un beso de Dick, Fernando Molano Vargas gana el Concurso Literario Cámara de Comercio de Medellín. Durante el escándalo paroxístico que asocia el VIH/SIDA con los hombres homosexuales, esta novela significa una bocanada de aire renovado para la literatura en Colombia y una afirmación de sí en el cuerpo homosexual. Molano invierte los valores: más que vergüenza inoculada, la homosexualidad es algo deseable para cualquier hombre. ${ }^{15}$

En un contexto plagado de incomprensión familiar, desprecio de la homosexualidad (por parte de compañeros, maestros, psicólogos, directivos y sacerdotes) y la ausencia de referentes - ausencia salvada con timidez por los futbolistas y sus piernas-, es donde dos adolescentes, Felipe y Leonardo, se forman a través de sentimientos recíprocos. Con frecuencia, en la novela aparecen alusiones a la ropa interior masculina, a los gestos varoniles, a la complexión corporal de los hombres y con todo esto se horada las restricciones en torno

15 A propósito de este tema, véase la novela póstuma, también de Molano Vargas (2012), Vista desde una acera. a lo que pueden y deben decir los homosexuales, por prudencia, sobre su deseo.

Al tiempo se ejerce una crítica a los modos como se organiza la vida social de los afectos. En una de las escenas más "incómodas", pero también una de las más seductoras y verdaderas, Felipe se dice a sí mismo:

En mi mano siento la botella de mi gaseosa. La miro. Leonardo ha bebido de ella... Besársela así a Leonardo: bajarle su pantalón despacio y besársela; acariciarle con mi lengua así: mucho rato... Levanto la botella muy lento, y me entra gaseosa en la boca: como si Leonardo se viniera en mi boca...: ¿a qué sabrá eso, Dios mío? Y me entra sensación de náusea: ¡qué estúpido: como si no lo deseara tanto! (Molano Vargas, 1992, p. 25).

“¿A qué sabrá eso?”, se pregunta Felipe. Y “eso” es lo que desea, porque proviene del cuerpo al que le profesa su amor.

Nueve años más tarde, César Álzate Vargas (2001), con La ciudad de todos los adioses, obtiene el premio en el V Concurso Literario Cámara de Comercio de Medellín para Antioquia. Una nostálgica narración en torno a la muerte y los adioses, en una ciudad que, a fuerza de su propia historia, parece no tener lugar para nada distinto a lo que se desvanece y se pierde sin retorno. Una ciudad de flores, muertos y hombres atraídos por hombres, con escasos referentes para resolver esa atracción de una manera no mortífera.

Por momentos, la novela de César Álzate Vargas se cruza con La Virgen de los sicarios de Fernando Vallejo (2006), para continuar un trayecto que es propio tanto en el estilo narrativo y escritural, como en la perspectiva con la que se lee la ciudad. Aquí, como en Un beso de Dick, el cuerpo es un texto. En él se escribe, por un lado, el abandono y la pérdida y, por otro, la vitalidad del deseo siempre renovado.

Entre distintos personajes que se encuentran y se separan, dos primos, Román y el Negro, son la metáfora de los encuentros masculinos que florecen un día para impregnar la memoria con el 
recuerdo del deseo. Tal vez por ello Nietzsche (2011) sostiene que no hay amor por lo que se desea, sino amor por el deseo.

Un cine de la ciudad es el espacio para que Román y el Negro hallen, en el otro cuerpo, algo de sí mismos:

Fueron a los baños. No había nadie allí. El Negro se metió en uno de los cubículos. Román no supo qué hacer. Invisibles cubos de hielo estremecían su cuerpo.

—Vení - le tuvo que decir el otro, y Román obedeció.

Cómo no, si el deseo era mayor que el miedo. Él mismo cerró la puerta y le pasó seguro.

El negro no dijo nada. Le desabrochó el botón del bluyín, le bajó el cierre, el pantalón, los interiores. Se agachó. Lo estudió, lo palpó; se precipitó un manantial de secreciones, que refregó en su cara.

-Mariquita, mariquita, lo que se da no se quita; y todo esto me lo diste a mí.

Se lo besó. Lento, un beso, dos, una caricia; lo arropó con su boca. Luego sus labios subieron por el cuerpo de Román, saboreándolo por encima de la camiseta. Le dio en el cuello una mordida susurrante, que produjo una electrocución en los músculos de Román. Él se asfixiaba (Alzate Vargas, 2001, pp. 125-126).

Para cerrar esta configuración, Los hombres no van juntos a cine de Manuel Valdivieso (2014). Si el escenario de Un beso de Dick es Bogotá y de La ciudad de todos los adioses es Medellín, en esta novela lo es Cúcuta. ${ }^{16}$

A través de Arturo Valdés, su personaje, Valdivieso logra una estimulante y hermosa reflexión retrospectiva sobre la homosexualidad en una ciudad que, como otras, acoge el paramilitarismo, el narcotráfico y el resentimiento de su impronta religiosa. Como un mantra, Emilio es el nombre que se repite una y otra vez. La novela se construye con base en el significado que este tiene en la

16 A propósito de Bogotá como escenario, se sugiere Narciso en vilo de Ignacio Zuleta Lleras (2010). Una novela sobre la relación entre dos hombres con edades dispares entre sí, que tiene como telón de fondo la violencia política en Colombia. vida de Arturo. Dos adolescentes que entre líneas cruzadas representan cómo se enamoran los hombres: olvidando que todos los muchachos tienen novia. Olvidando que todos tienen padres que confirman la hombría de sus hijos en una cita con las putas. Olvidando que todos, alguna vez, tendrán que negar lo que realmente aman. Emilio lanza un guiño para Arturo con recurso a la poesía - una hermosa referencia a Raúl Gómez Jattin-, como queriendo indicar que solo los que comprenden saben por qué con Gómez Jattin se declara el amor entre los hombres. A través de Gómez Jattin, acariciar la tristeza, la nostalgia y el miedo para saltar los umbrales prohibidos. El cuerpo como testigo y testimonio de lo que se ama.

Al final, dos imágenes: Arturo y Emilio separados por el desprecio cultural y los restos de un amor que amenaza esfumarse, salvo por la función redentora de la escritura:

Mientras el vómito salía y salpica el blanco, inmaculado y aséptico del inodoro, no solo percibí en mi lengua el sabor amargo de los ácidos estomacales mezclados con la comida, también saboreaba, ¡saboreaba! el sexo de Emilio, el lubricante de su pene, el delicioso veneno de sus besos, de su saliva. Arrodillado, estiré la mano para soltar el agua. Con ella se iba la última gota que quedaba de Emilio dentro de mi cuerpo. En ese momento, pensé, los restos de mi amor navegan en el subsuelo, en las cloacas de Cúcuta, rumbo a no sé qué desconocidos e ignotos parajes (Valdivieso, 2014, p. 204).

Sedgwick (2003) interroga por la función de lo fecal en la obra de Henry James. Esta interrogación se remite a la percepción de su textura. Más todavía, percibir es la formación de un saber sobre algo. Es el discernir si ese algo es asible o escurridizo, recio o suave, áspero o delicado. ¡Penetrable! En palabras de Sedgwick, percibir es tocar y tocar/ encontrar(se) otro cuerpo es iniciar el amor.

En estas tres novelas, mucho del amor entre los hombres se verifica en el sexo, el olor y la viscosidad de los productos corporales. En efecto, las novelas narran los temores asociados a la educación que reciben los hombres para despreciar el 
cuerpo de los otros hombres e imponerse el deseo por el cuerpo de las mujeres. Sin embargo, Molano, Alzate Vargas y Valdivieso expresan que los hombres se aman en el intercambio de aquellos materiales culturalmente nombrados como "desechos". ${ }^{17}$ Los hombres deben traspasar el umbral de lo culturalmente reconocido para hallarse a sí mismos.

El amor, un dios que resiste toda definición, es el rechazo a experimentar repugnancia por lo que producen los cuerpos que se aman. Esto puede reiterarse con el aforismo 134 de Más allá del bien y del mal; aquí Nietzsche (2011) invierte toda la filosofía, al declarar que es de los sentidos de donde dimana toda buena conciencia, toda verdad.

\section{Fuga}

Un mundo huérfano de Giuseppe Caputo (2016) cierra esta selección propuesta dentro de una posible genealogía de novelas de temática homosexual en Colombia. González Montero (2014) sostiene que una fuga es un modo de resistencia difusa. Una pulsión salvaje que, expresada en una imagen, es la vida allí donde

[...] se muestra a través de aquello que le es más cercano y al tiempo más heterogéneo: no su opuesto, sino el diluvio que es la vida misma y que impulsa todo desastre, pero también toda alegría (González Montero, 2014, p. 118).

La novela puede entenderse como una fuga, un devenir imperceptible en un lenguaje profusamente rico para nombrar la pobreza y el amor.

Dos hombres, padre e hijo, en una infinita pobreza, se entregan un amor único y singular que parece

17 Pese a la exasperación que produce al escritor Pablo Montoya (2016) el que la verga o el semen sean expresiones escriturales. Exasperación que ilustra lo que es la crítica literaria convertida en una técnica pedagógica de conducción, que establece qué debe decirse y cómo debe ser dicho. Causa gracia imaginar a Pablo Montoya corrigiendo el lenguaje de Henry James o de Paul Celan. En este punto, como bien acierta Carvajal (2000), cierta literatura, que por lo demás se presenta superior, esquiva referirse a la homosexualidad de un modo distinto al que se le tolera. llenar el mundo. Las teorías sociológicas del parentesco y del género, que tanto rechaza Fernando Vallejo, hacen dogma en torno al conflicto irresoluble entre el padre y el hijo varón. Pero Caputo despliega un gesto capaz de resistirlas sin proponérselo. Un mundo buérfano muestra otra cosa, más delicada y más definitiva: el abismo por donde se hunden los conceptos y sus fantasmas. Al final, una declaración:

Sigo en la cama, su cama, pensando en las últimas noches. Pienso en mi padre — todo es mi padre-, que ha estado más desde que no está. Eso es mentira: mi padre estaba más cuando estaba [...]. Vivo dormido para soñar con él (Caputo, 2016, p. 215).

Si el coraje que Caputo enarbola con su novela tiene comparación, si puede inscribirse en alguna genealogía, debe buscarse en El cadáver de papá de Jaime Manrique Ardila (1978) y en El hijo de Loth del francés François-Paul Alibert (2016).

\section{Entre hombres}

Hoy estas alli en la intimidad de mi hamaca tendido como un fauno priápico y soñoliento el cuerpo de tu virilidad entregada Raúl Gómez Jattin (2007, p. 111)

Las novelas aquí reseñadas, y los gestos que representan para una genealogía de la literatura de temática homosexual en Colombia, son importantes por distintos aspectos. De momento, considérese cuatro de ellos: el primero es de tipo epistémico. Esto quiere decir que estas novelas son importantes insumos para estudiar a Colombia a través de la manera como se interpreta la "cuestión" homosexual. En esta medida, las escenas mostradas al comienzo del artículo y que citan figuras como Luis López de Mesa, Israel Rojas, Pedro Restrepo Peláez y Miguel Echeverry, ilustran el pulso con el cual la homosexualidad es tratada y frente al que la literatura responde.

El segundo se asocia a la oportunidad de que los hombres, por medio de la literatura, construyan referentes para lo que se les ha enseñado a despreciar. En el caso de los homosexuales, lo que 
se enseña es el desprecio por sí mismos. Podría pensarse que esto sea poco. Sin embargo, como refiere Ahmed (2009), la importancia no estriba en la infelicidad o en los amores frustrados de las novelas, sino en poder hallar diferentes escrituras y estilos que no cesan de denunciar el desprecio mortífero que sistemáticamente somete a la homosexualidad y a los homosexuales.

El tercer aspecto remite a lo que desbroza el texto literario: el hombre solamente se afirma y se hace dueño de sí mismo cuando pierde el temor a ser despreciado. Por necesidad, la homosexualidad debe hacer fuerte a los hombres para derrotar la mirada del desprecio. Nietzsche lo expresa de manera magistral:

En el fuego del desprecio. Un nuevo paso hacia la independencia es atreverse a exteriorizar pareceres que pasan por vergonzosos para quien los abriga; hasta los amigos y conocidos suelen alarmarse entonces. La naturaleza dotada debe pasar también por este fuego: luego se pertenece mucho más aún a sí misma (2013, p. 258).

Para finalizar, combatir una pasión a la que se le declara extraña y equívoca es un ataque contra la vida (Nietzsche, 2001). Por eso, la fuerza de un hombre se verifica cuando convierte en suya la búsqueda de respuestas a la pregunta por cómo embellecer las pasiones; el hombre fuerte las cultiva, desoyendo el mandato que solicita extirparlas. Es decir, el trabajo del ser humano consigo mismo consiste en hermosear todo lo que la vida hace florecer para él. Lo que quiere una voluntad es afirmar su diferencia, sostiene Deleuze (2012). Lo que está en juego con esta idea es la determinación por responder a la pregunta cómo llega un hombre a convertirse a sí mismo en la obra que debe crear. La cuestión no reposa en la introspección o en una subjetividad vuelta sobre sí, sino en la lucha por darse valores y prácticas que expresen el delicado matiz de la propia diferencia.

\section{Referencias}

Abello, I. (2003). Violencias y cultura. Seguido de dos estudios sobre Nietzsche y Foucault. A propósito del mismo tema. Bogotá: Alfaomega.
Ahmed, S. (2009). Happiness and queer politics. World Pictures, (3), 1-19. Recuperado de http://www. worldpicturejournal.com/WP_3/TOC.html

Ahmed, S. (2015). La politica cultural de las emociones. México: UNAM.

Alibert, F.-P. (2016). El hijo de Loth. (Traducción de Miguel Betancourt). Medellín: Ediciones Unaula.

Álvarez Gardeazábal, G. (2014). La misa ha terminado. Medellín: Unaula.

Alzate, C. (2002). ¿Qué hace a una literatura homosexual? Universitas Humanistica, 53(1), 132-143.

Alzate Vargas, C. (2001). La ciudad de todos los adioses. Medellín: Cámara de Comercio.

Ángel, F. (1975). Te quiero mucho poquito nada. Medellín: El autor.

Anónimo (1994). Zohar. libro del esplendor (Traducción de Esther Cohen). México: Conaculta.

Arévalo Martínez, R. (1963). El hombre que parecía un caballo y otros cuentos. Guatemala: José de Pineda Ibarra.

Arias Trujillo, B. (2012a). En carne viva. Manizales: Fusión Comunicación Gráfica.

Arias Trujillo, B. (2012b) Por los caminos de Sodoma. Confesiones intimas de un homosexual. Manizales: Fusión Comunicación Gráfica.

Atala, K. (2014). The Woman who Knew Nietzsche. United States: Createspace.

Ávila Crespo, R. (2008). "Un lenguaje mímico de los afectos": la distorsión del lenguaje y la mirada del resentimiento. $\Delta \alpha i \mu \omega v$. Revista de Filosofía, 45, 23-39.

Balderston, D. (2004). El deseo, enorme cicatriz luminosa. Ensayos sobre homosexualidades latinoamericanas. Buenos Aires: Beatriz Viterbo.

Balderston, D. (2006). Baladas de la loca alegría: literatura queer en Colombia. En J. Serrano Amaya (Ed.), Otros cuerpos, otras sexualidades (pp. 16-33). Bogotá: Pontificia Universidad Javeriana, Pensar.

Balderston, D. (2015). Los caminos del afecto. Bogotá: Instituto Caro y Cuervo.

Barba-Jacob, P. (1983). Antorchas contra el viento: poesía completa y prosa selecta. Medellín: Gobernación de Antioquia.

Benjamin, W. (2010). Calle de dirección única. En Obras. (libro IV/vol. 1, pp. 23-89). Madrid: Abada.

Bersani, L. (1989). Homos. Buenos Aires: Manantial. 
Borovinsky, T., y Taub, E. (2009). Biopolítica y nazismo. Una lectura del genocidio moderno. En: I. Mendiola Gonzalo (Ed.), Rastros y rostros de la biopolitica (pp. 96-111). Barcelona: Anthropos.

Caputo, G. (2016). Un mundo huérfano. Bogotá: Random House.

Carvajal, A. (2015) Ruega por nosotros. Bogotá: Ediciones B.

Carvajal, E. (2000). Elementos del erotismo en varios cuentos de Andrés Caicedo. Íkala. Revista de Lenguaje y Cultura, 5(1), 143-158.

Castro García, Ó. (2004). Un siglo de erotismo en el cuento colombiano -antologia-. Medellín: Universidad de Antioquia.

Castro Gómez, S. (2007). Disciplinar o poblar. La intelectualidad colombiana frente a la biopolítica (1906-1934). Nómadas, (26), 44-55.

Deleuze, G. (1980). Diálogos. Valencia: Pre-Textos.

Deleuze, G. (2006). Conversaciones. Barcelona: Pre-Textos.

Deleuze, G. (2012). Nietzsche y la filosofía. Barcelona: Anagrama.

Deleuze, G., y Guattari, F. (2004). El anti Edipo. Capitalismo y esquizofrenia. Barcelona: Paidós.

Derrida, J. (1981). Espolones. Los estilos de Nietzsche. Barcelona: Pre-Textos.

Díaz Ruiz, F. (2010). La identidad gay de una drag queen globalizada en Al diablo la maldita primavera de Alonso Sánchez Baute. Estudios de literatura colombiana, (26), 95-108.

Diethe, C. (1996). Nietzsche's Women: Beyond the Whip. Berlin: De Gruyter.

Echeverry, M. (1971) Psicopatología y existencia del hippie. Bogotá: Instituto Bioquímico.

Ferro Bayona, J. (2004). Nietzsche y el retorno de la metáfora. Barranquilla: Ediciones Uninorte.

Forster, F. W., y Giraldo, M. (1934). Ética y pedagogias sexológicas. Conferencia sobre educación sexual. Medellín: Tipografía Industrial.

Foucault, M. (1996). La vida de los hombres infames. Buenos Aires: Caronte.

Foucault, M. (2015). ¿Qué hacen los hombres solos? Madrid: Ediciones Cinca.

Friedman, D. M. (2007). Con mentalidad propia. Historia cultural del pene. Barcelona: Península.

García Valdivieso, G. (2010). Los putos castos. Memorias inconfesables de un doble discurso. Bogotá: Banana Rosa.
García Valdivieso, G. (2016). Tres hombres, dos padres y un hijo. Bogotá: Ediciones $\mathrm{B}$.

Gómez, J. (1977). Uno bajo el signo de Escorpión. Confidencias. Pereira: Sigma.

Gómez Jattin, R. (2007). Amanecer en el valle del Sinú. Antología poética. Bogotá: Fondo de la Cultura Económica.

González Iglesias, J. (2001). Introducción. En J. Gil-Albert (Aut.), Heracles. Sobre una manera de ser (pp. 7-22). Valencia: Pre-Textos.

González Montero, S. A. (2014). Líneas de fuga: transformación y cambio social. Revista Estudios Politicos, (45), 115-133.

Hincapié García, A. (2009). Consecuencias pedagógicoformativas a propósito de una lectura de Un beso de Dick. Pedagogía y Saberes, (28), 99-109.

Hincapié García, A. (2011). Por los caminos de Sodoma. Discurso de réplica, promesa formativa para una homosexualidad (1932). Revista de Estudios Sociales, (41), 44-55.

Hincapié García, A. (2015), Revisiones críticas al concepto de género. Apuntes para la teoría social contemporánea. Universitas Humanistica, (79), 15-40.

Hoyos, H. (1973). Nadie conoce mi sexo. Cali: El autor.

Kofman, S. (1994). El desprecio de los judios. Nietzsche, los judios, el antisemitismo. Madrid: Arena Libros.

Lemm, V. (2013). Nietzsche y el pensamiento politico contemporáneo. Chile: Fondo de Cultura Económica.

López de Mesa, L. (1926). Civilización contemporánea. París: Agencia Mundial de Librería 14, Rue de Saints-Pères.

Manrique Ardila, J. (1978). El cadáver de papá. Bogotá: Instituto Colombiano de Cultura.

May, S. (2011). Nietzsche's on the Genealogy of Morality. United Kingdom: Cambridge University Press.

Meyer, H. (1977). Historia maldita de la literatura. Madrid: Taurus.

Milner, J-C. (2008). El judio de saber. Buenos Aires: Manantial.

Molano Vargas, F. (1992). Un beso de Dick. Medellín: Cámara de Comercio de Medellín.

Molano Vargas, F. (2012). Vista desde una acera. Bogotá: Seix Barral.

Montoya, P. (2016). Una mediocre novela sobre homosexualidad. Boletín Cultural y Biográfico, 50(91), 138-139. 
Nehamas, A. (2002). Nietzsche. La vida como literatura. México: Fondo de Cultura Económica.

Nietzsche, F. (2001). Crepúsculo de los idolos. Madrid: Alianza.

Nietzsche, F. (2005). La genealogía de la moral. Madrid: Alianza.

Nietzsche, F. (2011). Más allá del bien y del mal. Madrid: Alianza.

Nietzsche, F. (2013). Humano, demasiado humano. Un libro para espiritus libres. Vol. I. Madrid: Akal.

Oliver, K y Pearsall, M. (1998). Feminist Interpretations of Friedrich Nietzsche. Pennsylvania: Pennsylvania State University Press.

Pater, W. (1999). El renacimiento. Estudios sobre arte y poesía. Barcelona: Alba.

Patton, P. (1993). Nietzsche, Feminism and Political Theory. Londres, Nueva York: Routledge.

Piñeres Sus, J. D. (2017). Lo humano como ideal regulativo. Imaginación antropológica: cultura, formación y antropología negativa. Medellín: Universidad de Antioquia.

Restrepo Peláez, P. (1969). El homosexualismo en el arte actual. Bogotá: Ediciones Tercer mundo.

Rojas, I. (1947). Los grandes azotes de la raza. (4. ${ }^{a}$ ed.) Manizales: Editorial Zapata.
Rujas Martínez-Novillo, J. (2010). Genealogía y discurso. De Nietzsche a Foucault. Nómadas, 26(2), 105-119.

Sánchez Baute, A. (2003). Al diablo la maldita primavera. Bogotá: Alfaguara.

Sedgwick, E. K. (1998). Epistemología del armario. Madrid: La Tempestad.

Sedgwick, E. K. (2002). A(queer) y ahora. En R. Mérida Jiménez (Ed.), Sexualidades transgresoras. Una antología de estudios queer (pp. 29-54). Barcelona: Icaria.

Sedgwick, E. K. (2003). Touching feeling. Affect, pedagogy, performativity. Londres: Duke University Press.

Uris, L. (1971). Éxodo. Barcelona: Círculo de Lectores.

Valdivieso, M. (2014). Los hombres no van juntos a cine. Bogotá: CAMM.

Vallejo, F. (2006). La Virgen de los sicarios. Bogotá: Alfaguara.

Vallejo, F. (2008). El desbarrancadero. Bogotá: Alfaguara.

Vallejo, F. (2010). El don de la vida. Bogotá: Alfaguara.

Vélez, R. (2001). Veinticinco centimetros. Novela pornometafísica. Bogotá: Proyecto Editorial.

Zuleta Lleras, I. (2010). Narciso en vilo. Bogotá: Rocca.

Zuleta Pardo, M. (2011). La voluntad de verdad en Colombia: una genealogía de las ciencias sociales profesionales. Bogotá: IESCO.

How to reference this article: Hincapié García, A. (2018). Responder al desprecio. Nietzsche y la genealogía de la literatura de temática homosexual en Colombia. Íkala, Revista de Lenguaje y Cultura, 23(3), 451-467. DOI: 10.17533/udea.ikala.v23n03a04 